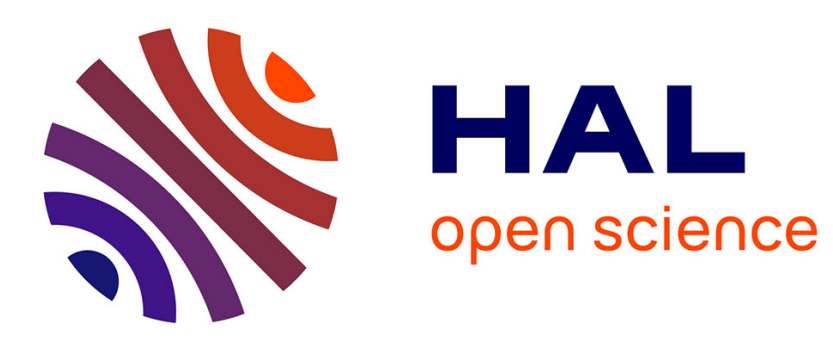

\title{
High increase in biodegradability of coking wastewater enhanced by Mn ore tailings in Fenton/O3 combined processes
}

H Liu, T Xu, C Li, W Liu, Eric Lichtfouse

\section{- To cite this version:}

H Liu, T Xu, C Li, W Liu, Eric Lichtfouse. High increase in biodegradability of coking wastewater enhanced by Mn ore tailings in Fenton/O3 combined processes. International Journal of Environmental Science and Technology, 2021, 18 (1), pp.173 - 184. 10.1007/s13762-020-02816-8 . hal-03291959

\section{HAL Id: hal-03291959 \\ https://hal.science/hal-03291959}

Submitted on 20 Jul 2021

HAL is a multi-disciplinary open access archive for the deposit and dissemination of scientific research documents, whether they are published or not. The documents may come from teaching and research institutions in France or abroad, or from public or private research centers.
L'archive ouverte pluridisciplinaire HAL, est destinée au dépôt et à la diffusion de documents scientifiques de niveau recherche, publiés ou non, émanant des établissements d'enseignement et de recherche français ou étrangers, des laboratoires publics ou privés. 


\title{
High increase in biodegradability of coking wastewater enhanced by $\mathrm{Mn}$ ore tailings in Fenton $/ \mathrm{O}_{3}$ combined processes
}

\author{
H. Liu' ${ }^{1} \cdot$ T. Xu ${ }^{1} \cdot$ C. Li ${ }^{1} \cdot$ W. Liu ${ }^{1} \cdot$ E. Lichtfouse ${ }^{2,3}$
}

\begin{abstract}
Coking wastewater contains high concentration of organic pollutants and seriously endangers the natural ecological balance and human health. This study proposes a novel pre-treatment method that can significantly improve removal efficiency of organic pollutants in coking wastewater by the concept of "treating waste with waste." Three two-step advanced oxidation processes were proposed by combining Fenton, ozonation with manganese tailings: (i) $\mathrm{O}_{3} / \mathrm{Mn}$ tailings $+\mathrm{H}_{2} \mathrm{O}_{2}$, (ii) $\mathrm{O}_{3} / \mathrm{Mn}$ tailings + Fenton and (iii) Fenton $+\mathrm{O}_{3} / \mathrm{Mn}$ tailings. Results show that (1) Fenton $+\mathrm{O}_{3} / \mathrm{Mn}$ tailings presented the best removal efficiency in the three combined processes. The reaction process was carried out by first performing Fenton reaction on the wastewater for $65 \mathrm{~min}$, and then, the reaction wastewater was subjected to ozone and manganese tailings mixed reaction for $30 \mathrm{~min}$, and the chemical oxygen demand (COD) and chromaticity were reduced by $61.0 \%$ and $96.1 \%$, respectively. (2) After pre-treated with Fenton, the biodegradability of the wastewater can be significantly increased. When Fenton $+\mathrm{O}_{3} / \mathrm{Mn}$ ore tailings were used to pre-treat the raw water, the biodegradability $\left(\mathrm{BOD}_{5} / \mathrm{COD}\right)$ of the wastewater was increased to 0.54 . It is proved that the combined process Fenton $+\mathrm{O}_{3} / \mathrm{Mn}$ ore tailings has better performance than the ordinary single advanced oxidation process. Compared with the existing methods, the addition of manganese tailings containing manganese oxides as catalytic free radicals can significantly improve the treatment activity of advanced oxidation process (AOPS).
\end{abstract}

\section{H. Liu}

Liuhb@usst.edu.cn

1 School of Environment and Architecture, University of Shanghai for Science and Technology, Shanghai 200093, China

2 Aix-Marseille Univ, CNRS, IRD, INRA, Coll France, CEREGE, 13100 Aix en Provence, France

3 State Key Laboratory of Multiphase Flow in Power Engineering, Xi' an Jiaotong University, Xi' an 710049, China 


\section{Graphic abstract}

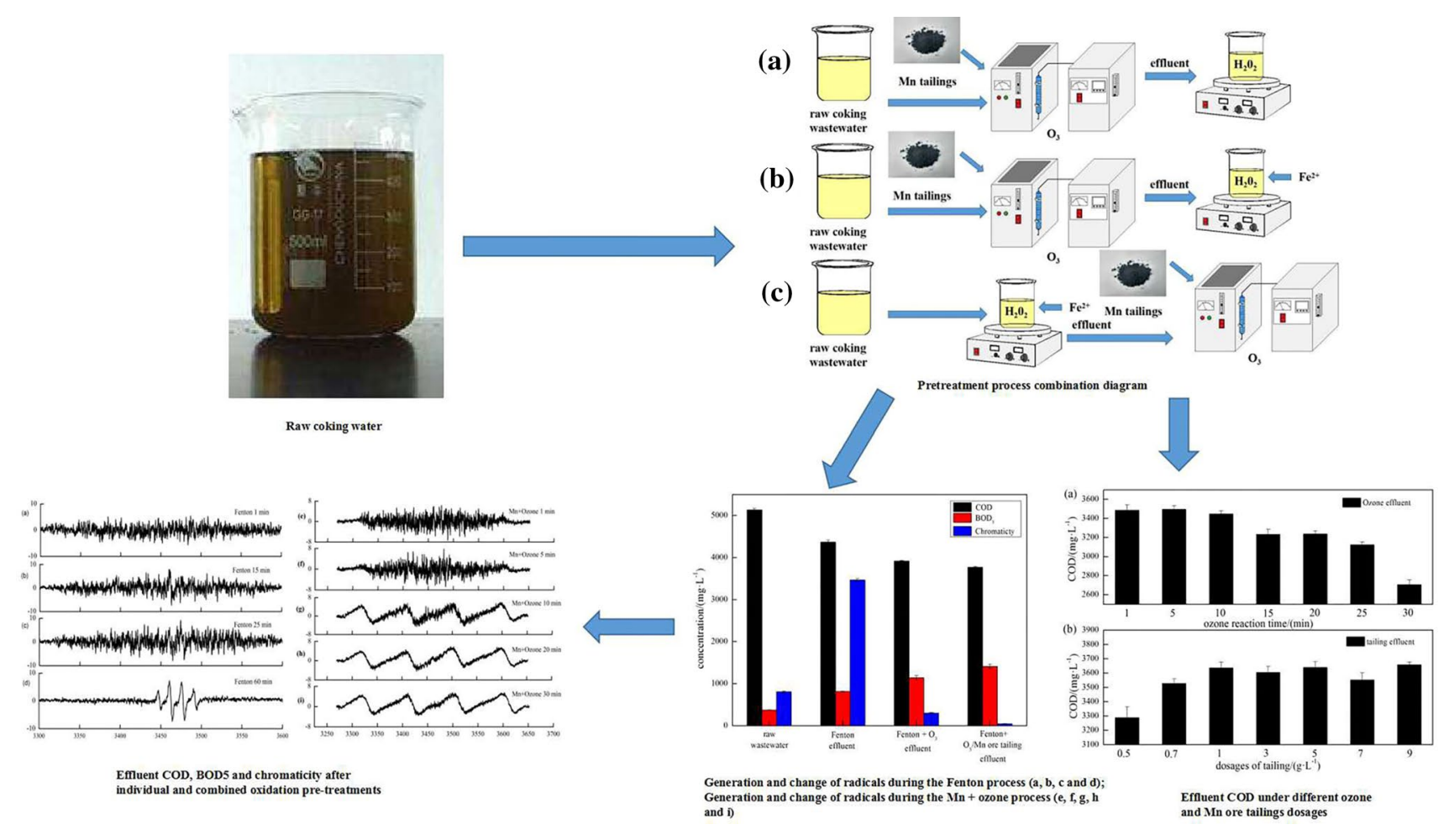

Keywords Coking wastewater $\cdot$ Pre-treatment processes $\cdot$ Biodegradability $\cdot$ Mn ore tailing $\cdot$ Combined advanced oxidation process (AOP)

\section{Introduction}

Coking wastewater is mainly produced from the process of high-temperature carbonization of coal, by-production recovery and refining, gas purification and other production processes (Meng et al. 2017). In China, for example, many coke plants and coal gasification plants cause annual discharge of 300 million tons of coking wastewater, which is one of the main sources of industrial wastewater discharge (Lungen 2005). Coking wastewater contains inorganic pollutants (ammonia, fluoride, cyanide, thiocyanate, heavy metals, etc.) and high concentrations of organic pollutants (phenol, amine, oil, naphthalene, quinoline, pyridine, etc.) (Lim et al. 2003; Wenzl et al. 2006). Most of these compounds are refractory, highly concentrated, toxic, mutative and carcinogenic and may produce long-term environmental and ecological impacts.

A certain number of refractory and inhibitory organic compounds (ammonia nitrogen, oily substances, volatile phenols and cyanide) in coking wastewater are highly concentrated, especially in the practical engineering treatment; large amount of cyanide contained in the coking wastewater often results in failure of the biological treatment processes since it is difficult for microorganisms to survive ( $\mathrm{Li}$ and Zhao 2001); pre-treatment processes are necessary to reduce toxic and harmful substances and further strengthen the biodegradability of coking wastewater. The conventional pretreatment methods include ammonium stripping, extraction, flotation and advanced oxidation processes (AOPs). The performance of the ammonium stripping process is difficult to control, and the process is easily affected by conventional indicators such as $\mathrm{pH}$ in the coking wastewater, resulting in unstable treatment (Guštin and Marinšeklogar 2011). The flotation process is mainly restricted by conventional factors such as coagulation and contact time (Santo et al. 2012).

Advanced oxidation methods have been applied in wastewater treatments, e.g., Fenton, ozonation, wet catalytic oxidation, photochemical oxidation and electrochemical oxidation (Asghar et al. 2015). Ozone $\left(\mathrm{O}_{3}\right)$ is considered to be one of the most powerful oxidants in alkaline solutions and is widely used for disinfection and elimination of organic compounds in water and wastewater 
(Barriga-Ordonez et al. 2006; Turhan and Uzman 2008). $\mathrm{O}_{3}$ molecules can react with organic compounds by direct oxidation, thereby improving the biodegradability of inhibitory compounds (Bijan and Mohseni 2005; Zhang et al. 2014). Fenton is the most widely used AOP, mainly using divalent iron ions catalyzing hydrogen peroxide and producing hydroxyl radicals $(\cdot \mathrm{OH})$. Hydroxyl radicals have strong oxidizing power and can degrade organic matter in wastewater. However, the removal of COD and ammonia nitrogen from coking wastewater by ozonation alone is insufficient, and its application is constrained by high equipment and operating costs. In the single Fenton process, low utilization of hydrogen peroxide and strict $\mathrm{pH}(2.0-4.0)$ is necessary, causing the process complex and expensive (Feng et al. 2006). Performances of single treatment technologies are limited due to complexity of the real coking wastewater; thus, the combination of different treatment units is necessary. The combination of Fenton and membrane treatment process could simultaneously remove organic matter and recover struvite from wastewater (Kumar and Pal 2012, 2013). At optimum operating conditions, maximum removal rates for COD, phenol and cyanide reached $84.7 \%, 88.5 \%$ and $79.3 \%$, respectively (Verma and Chaudhari 2020), while the COD removal rate can reach $71.0 \%$ when coking wastewater pre-treated with a combination of electro-Fenton process (Zhao et al. 2019).

Manganese ore tailings were produced hundreds of thousands of tons every year in China, due to the exploitation of manganese ores. It causes serious environmental problems, such as occupying land resources, damaging the natural landscape, inducing geological disasters and producing chemical wastes (Liu et al. 2012). Manganese ore tailings may also be used as oxidant in wastewater treatment, which provides not only an effective residual management option for manganese ore tailings, but also a beneficial approach for the ecology environment. It has been reported that transition metals such as copper $(\mathrm{Cu})$, manganese (Mn) and their oxides could be a replacement for iron ions in the Fenton process (Faweya and Oniya 2012; Su et al. 2016). Therefore, the application of Mn ore tailings in combined advanced oxidation processes might be a promising pre-treatment for coking wastewater, by disposing Mn ore tailings and coking wastewater simultaneously with a low cost. In a Mn-AOP system, Mn ore tailings can act as catalysts and generate $\cdot \mathrm{OH}$ by consuming hydrogen peroxide. Although traditional AOPs and their combination processes have been widely used for the pre-treatment of coking wastewater, the Mn-AOP is rarely reported.
This study aims to screen a suitable cost-effective process disposing $\mathrm{Mn}$ ore tailings and coking wastewater simultaneously by using $\mathrm{Mn}$ in the ore tailings as a catalyst combining with AOPs. Three combination processes were investigated, i.e., (i) $\mathrm{O}_{3} / \mathrm{Mn}$ ore tailings $+\mathrm{H}_{2} \mathrm{O}_{2}$, (ii) $\mathrm{O}_{3} /$ Mn ore tailings + Fenton and (iii) Fenton $+\mathrm{O}_{3} / \mathrm{Mn}$ tailings. In this paper, the treatment characteristics and reaction mechanism of advanced oxidation combined with manganese tailings as catalyst were studied.

\section{Materials and methods}

\section{Characteristics of coking wastewater}

The raw coking wastewater was collected from the equation tank of QJ Coking Chemical Plant (Yunnan, China), and it is an untreated production wastewater produced during the tar processing, mainly consists of steam condensate and crude gas final cooling water. Its characteristics are listed as follows: COD of $5100.0 \pm 100.0 \mathrm{mg} \mathrm{L}^{-1}$, $\mathrm{BOD}_{5}$ of $370.0 \pm 20.0 \mathrm{mg} \mathrm{L}{ }^{-1}$, pH of $6.5-6.8$, $\mathrm{NH}_{4}{ }^{+}-\mathrm{N}$ of $430.0 \pm 10.0 \mathrm{mg} \mathrm{L}^{-1}$ and chromaticity of $800.0 \pm 50.0 \mathrm{mg} \mathrm{L}^{-1}$.

\section{Characteristics of Mn ore tailings}

The raw Mn ore tailings were obtained from a mine in Guangxi, China. The main components of the tailing are $\mathrm{SiO}_{2}$ (silicon dioxide) and $\mathrm{MnO}_{2}(\mathrm{Mn}$ dioxide). Shape and structure of the tailing were identified by SEM (scanning electron microscope) in our previous research (Liu et al. 2015). Before used in experiments, the tailings were dried at $105{ }^{\circ} \mathrm{C}$ for $24 \mathrm{~h}$ and then sieved through a $100-200$ mesh sieve.

\section{Experimental methods}

\section{Comparison of individual and combined oxidation pre-treatments}

For individual Fenton pre-treatments, initially $100 \mathrm{~mL}$ of coking wastewater was put into a glass breaker of $250 \mathrm{~mL}$ and the $\mathrm{pH}$ was adjusted to $4.0 \mathrm{using} 1 \mathrm{M} \mathrm{HCl}$ solution. Then, hydrogen peroxide and $\mathrm{FeSO}_{4}$ were added to each breaker to make the final concentration of $2 \mathrm{~g} \mathrm{~L}^{-1}$ and $0.7 \mathrm{~g} \mathrm{~L}^{-1}$, respectively, under moderate mixing $(150 \mathrm{rpm})$ 
with magnetic stirring apparatus (HJ-6, Jintan, China). After the Fenton treatment run for $2 \mathrm{~h}, \mathrm{O}_{3}$ was applied at a flow rate of $2 \mathrm{~L} \mathrm{~min}^{-1}$ for $30 \mathrm{~min}$. The $\mathrm{O}_{3}$ concentration was $25 \mathrm{mg} \mathrm{L}^{-1}$, which was supplied by using an $\mathrm{O}_{3}$ generator ( $\mathrm{YH}-\mathrm{X}-15 \mathrm{P}$, Aoyang, China). Another trial was performed by combining Fenton and $\mathrm{O}_{3} / \mathrm{Mn}$ ore tailings oxidation. After Fenton reaction, $0.2 \mathrm{~g}$ of $\mathrm{Mn}$ ore tailings was added to $100 \mathrm{~mL}$ Fenton effluent, and then subject to $30 \mathrm{~min}$ of $\mathrm{O}_{3}$ reaction. The flow rate of $\mathrm{O}_{3}$ was $1.5 \mathrm{~L} \mathrm{~min}^{-1}$.

\section{Three trials of two-step combined oxidation processes}

Three combination methods were conducted, i.e., (i) $\mathrm{O}_{3} / \mathrm{Mn}$ ore tailings $+\mathrm{H}_{2} \mathrm{O}_{2}$, (ii) $\mathrm{O}_{3} / \mathrm{Mn}$ ore tailings + Fenton and (iii) Fenton $+\mathrm{O}_{3} / \mathrm{Mn}$ ore tailings. The combination (i) is shown in Fig. S1a: $100 \mathrm{~mL}$ raw coking wastewater was treated with $\mathrm{O}_{3} / \mathrm{Mn}$ ore tailings for $30 \mathrm{~min}$, then added $2 \mathrm{~g} \mathrm{~L}^{-1}$ of $\mathrm{H}_{2} \mathrm{O}_{2}$ to the solution and reacted for $2 \mathrm{~h}$. The combination (ii) is represented in Fig. S1b: $100 \mathrm{~mL}$ raw coking wastewater was treated with $\mathrm{O}_{3} / \mathrm{Mn}$ ore tailings for $30 \mathrm{~min}$; then, Fenton reagent with $2 \mathrm{~g} \mathrm{~L}^{-1}$ hydrogen peroxide and $0.7 \mathrm{~g} \mathrm{~L}^{-1} \mathrm{FeSO}_{4}$ was put to the effluent, reacting for $2 \mathrm{~h}$. The combination (iii) is presented in Fig. S1c: $100 \mathrm{~mL}$ of raw coking wastewater was treated with Fenton reagent with $2 \mathrm{~g} \mathrm{~L}^{-1}$ hydrogen peroxide and $0.7 \mathrm{~g} \mathrm{~L}^{-1} \mathrm{FeSO}_{4}$ for $2 \mathrm{~h}$; then, the effluent was treated with $\mathrm{O}_{3} / \mathrm{Mn}$ ore tailings for $30 \mathrm{~min}$. All three reaction conditions were controlled to room temperature, and the profiles of chromaticity and other indicators during the reaction were investigated.

\section{Optimization of each oxidation step for combination (iii)}

To further improve the efficiency of the combined oxidation process (iii), each step was optimized sequentially. Firstly, the mass ratio of hydrogen peroxide and $\mathrm{Fe}^{2+}$ was optimized via operational runs with the initial dosage mass ratios of $1: 2,1: 1,2: 1,4: 1,6: 1,8: 1$ and 10:1, respectively, while the $\mathrm{H}_{2} \mathrm{O}_{2}$ dosage is optimized from 1.0, 2.0, 3.0, 4.0, 5.0, 6.0 and $7.0 \mathrm{~g} \mathrm{~L}^{-1}$. The ozonation contact time was optimized from 15, 20, 25 and $30 \mathrm{~min}$, and the dosage of $\mathrm{Mn}$ ore tailings was optimized from $0.5,0.7,1.0,3.0,5.0,7.0$ and $9.0 \mathrm{~g} \mathrm{~L}^{-1}$. The used Mn ore tailings were recovered from the reaction mixture by filtration and then washed with distilled water for three times and dried at $105^{\circ} \mathrm{C}$ for $24 \mathrm{~h}$ and then screened through a 100-200 mesh sieve.

\section{Recycling of the used Mn ore tailing}

The used Mn ore tailings were recovered from the reaction mixture by filtration washed with distilled water for three times and dried at $105^{\circ} \mathrm{C}$ for $24 \mathrm{~h}$ in a vacuum oven and then screened through a 100-200 mesh sieve. The reuse experiments were performed according to the process of the combination (iii). After reuse, the Mn ore tailing was added in a glass breaker with $100 \mathrm{ml}$ pure water under moderate mixing rate $(150 \mathrm{rpm})$ with magnetic stirring apparatus to detect residue metal ions in the leaching solution.

\section{Analytical methods}

COD was digested by a Hach reagent tube (model 20-1500 mg/L) and was measured by a matching spectrophotometer; $\mathrm{BOD}_{5}$ is determined by a dilution inoculation method, while the ozone concentration was determined by the KI solution ( $\left.10 \mathrm{~g} \mathrm{~L}^{-1}\right)$ method; the chromaticity is determined by the dilution factor method, and $\mathrm{pH}$ was measured using a Mettler Toledo FE20. Phenol, phenylamine and other organic components in the coking wastewater were determined by a gas chromatography-mass spectrometer (GC-MS, Agilent Technologies 7890A, USA). The samples were extracted using $\mathrm{CH}_{2} \mathrm{Cl}_{2}$, filtered through a $0.45 \mu \mathrm{L}$ syringe filter (PTFE) and then separated using a $30 \mathrm{~m} \times 250 \mu \mathrm{m}$ capillary chromatographic column. Helium of $1.0 \mathrm{~mL} \mathrm{~min}{ }^{-1}$ was used as carrier gas with a splitless injection volume of $2 \mu \mathrm{L}$ and inlet temperature of $250{ }^{\circ} \mathrm{C}$. The oven temperature was programmed at $40{ }^{\circ} \mathrm{C}$ for $5 \mathrm{~min}$ and then ramped at $10^{\circ} \mathrm{C} \mathrm{min}$ min $^{-1}$ to $150{ }^{\circ} \mathrm{C}$ with 2 min, increased at a rate of $5^{\circ} \mathrm{C} \min ^{-1}$ to $280{ }^{\circ} \mathrm{C}$, and kept for $3 \mathrm{~min}$ (Liu et al. 2016a). Radicals and metal ions were detected with

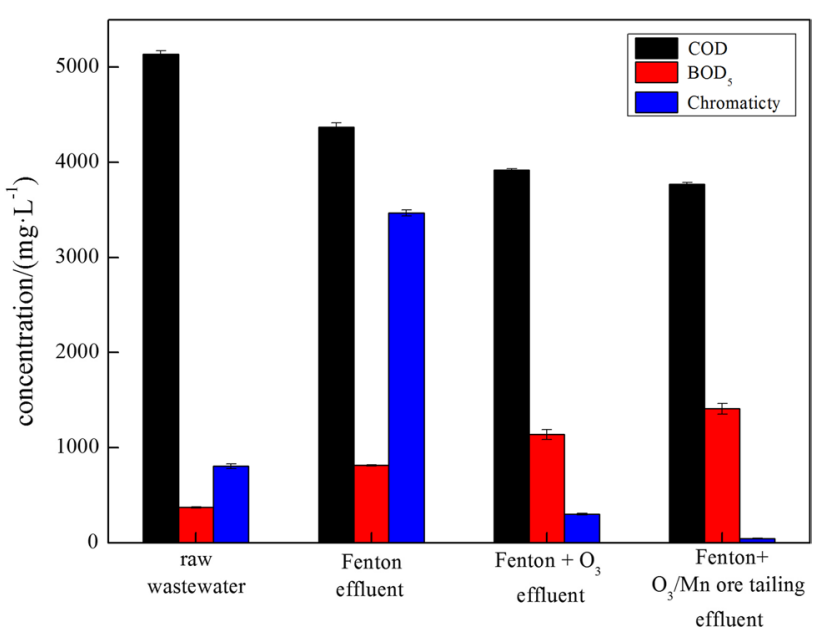

Fig. 1 Effluent COD (chemical oxygen demand), $\mathrm{BOD}_{5}$ (biochemical oxygen demand) and chromaticity after individual and combined oxidation pre-treatments (note the increase in $\mathrm{BOD}_{5}$ and the decrease in COD) 
a Micro-ESR (Active Spectrum Inc, USA) using $100 \mathrm{mM}$ of DMPO (5,5-dimethyl-1-pyrroline N-oxide) and ICP-MS (inductively coupled plasma mass spectrometry) (PE/Nexlon 300X, PE, USA). Other chemical and physical parameters of the water sample were determined according to the standard methods (Gilcreas 1966).

\section{Results and discussion}

\section{Enhancing effect of Mn ore tailings on Fenton and ozonation}

From results shown in Fig. 1, COD removal rate of the individual Fenton oxidation was only around $15 \%$, meanwhile the chromaticity was increased from 800 to 3500 due to iron blue formation by reaction of iron in Fenton and cyanide in coking wastewater. Figure 1 also indicates that the combination of Fenton with ozonation and/or the Mn ore tailings can largely enhance the pre-treatment performance. This is because manganese tailings promote catalytic oxidation of organic wastewater and can remove phenols, sulfides and COD in coking wastewater. $\mathrm{O}_{3}$ is highly oxidizing and can react quickly with organic matter to achieve COD removal. Compared with the single Fenton method, COD decreased by $496 \mathrm{mg} \mathrm{L}^{-1}$, BOD 5 increased by $331 \mathrm{mg} \mathrm{L}^{-1}$ and chromaticity decreased by 3200 , respectively, when using Fenton $+\mathrm{O}_{3}$ as the pre-treatment process. Surprisingly, COD decreased by $617 \mathrm{mg} \mathrm{L}^{-1}, \mathrm{BOD}_{5}$ increased by $593 \mathrm{mg} \mathrm{L}^{-1}$ and chromaticity decreased by 3460, respectively, when using Fenton $+\mathrm{O}_{3} / \mathrm{Mn}$ tailings as the pre-treatment process. Two options are obviously available to improve the pollutants removal efficiencies of coking wastewater: (1) optimizing the Fenton reaction conditions; (2) combing Mn ore tailings with the traditional oxidation processes such as Fenton and ozonation.

Figure 2 illustrates the optimization results of the Fenton process by using effluent COD as a model parameter at different $\mathrm{H}_{2} \mathrm{O}_{2} / \mathrm{Fe}^{2+}$ ratios and reaction times. As shown in Fig. 2a, the different ratios of hydrogen peroxide and ferrous ion had a significant effect on effluent COD. Higher COD removal rate could be obtained when the ratio is $1: 1$. The reaction time of Fenton has a positive effect on the removal of COD, but when the reaction time reaches $65 \mathrm{~min}$, the effluent COD is relatively stable. It is shown that at $65 \mathrm{~min}$, the reaction has been completed and the maximum removal rate of COD is achieved (Fig. 2b). Hydroxyl radicals produced by the Fenton reagent have a strong oxidizing capacity and can react with organic matter quickly in the early period. The effect of $\mathrm{H}_{2} \mathrm{O}_{2}$ concentration on removal of COD was investigated in the range of 1.0-7.0 $\mathrm{g} \mathrm{L}^{-1}$ as shown in Fig. 2c. With the increase in $\mathrm{H}_{2} \mathrm{O}_{2}$ dosage, effluent COD of the coking wastewater decreased due to the higher concentration of hydrogen peroxide that can produce more -OH (Peng et al. 2017; $\mathrm{Zhu}$ et al. 2011). At the same time, excessive concentration of $\mathrm{H}_{2} \mathrm{O}_{2}$ is not an option considering the cost factor. When the concentration of $\mathrm{H}_{2} \mathrm{O}_{2}$ exceeds $5.0 \mathrm{~g} \mathrm{~L}^{-1}, \mathrm{Fe}^{2+}$
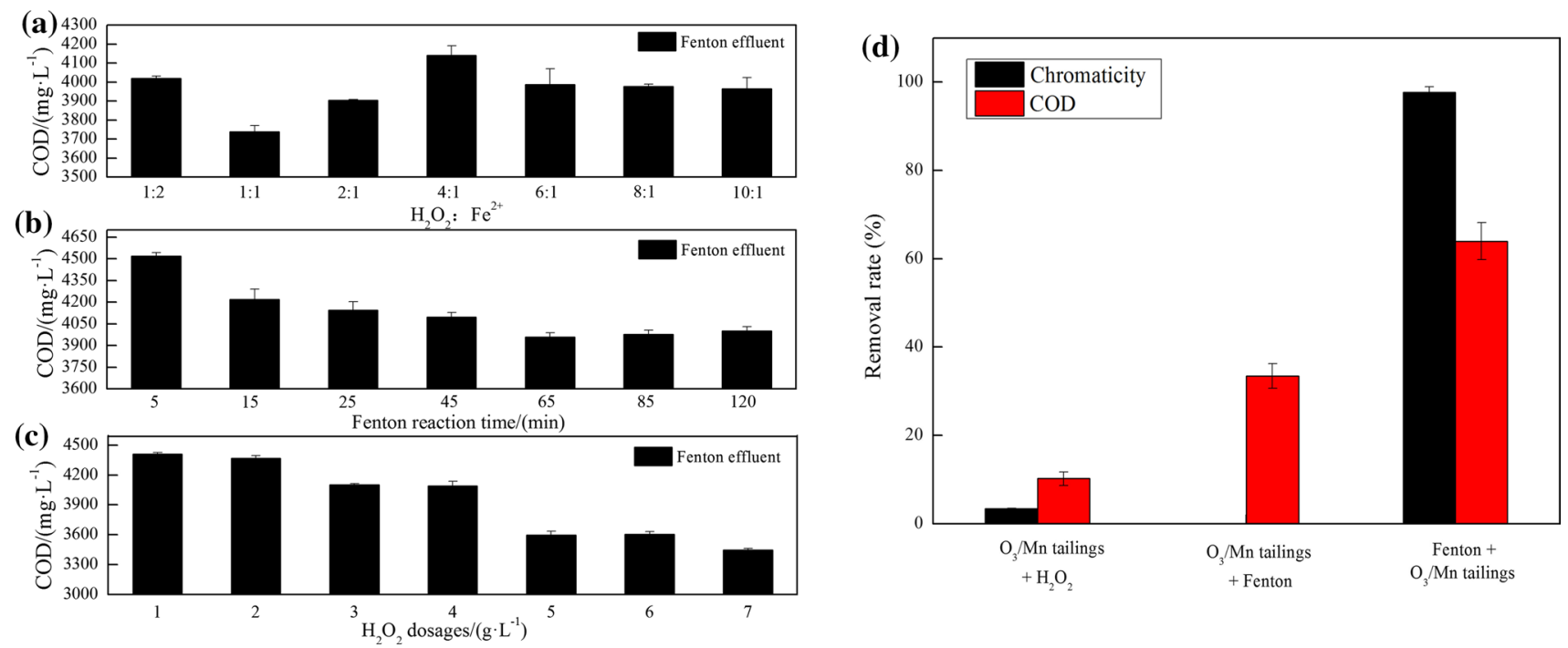

Fig. 2 Effluent COD (chemical oxygen demand) after different Fenton conditions (a-c); effluent COD (chemical oxygen demand) and chromaticity of different combination processes (d) (note the decrease in COD) 
is almost completely consumed, and the effluent COD is maintained at $3400-3500 \mathrm{mg} \mathrm{L}^{-1}$. Through the optimization of Fenton process, the removal rate of COD in effluent was increased from 21.5 to $30.0 \%$.

Based on the best Fenton results obtained from the above reaction, three complex oxidation experiments were carried out. The experimental control $\mathrm{O}_{3}$ concentration and contact time were $25 \mathrm{mg} \mathrm{L}^{-1}, 30 \mathrm{~min}$, respectively, while the manganese tailings dosage and reaction time were $0.5 \mathrm{~g} \mathrm{~L}^{-1}$ and $30 \mathrm{~min}$, respectively. Figure $2 \mathrm{~d}$ indicates that COD and chromaticity removal rates varied greatly with different combined oxidation processes. For the first group of experiments, Mn ore tailings were dosed simultaneously with subject to $30 \mathrm{~min}$ of ozonation and then reacted for $30 \mathrm{~min}$ with hydrogen peroxide. Removal rates of COD and chromaticity are only $9.3 \%$ and $3.3 \%$, respectively, for the first group of experiments. For the second group of experiments, Mn ore tailings were dosed simultaneously with subject to ozonation for $30 \mathrm{~min}$; Fenton reagent was then added and reacted for $30 \mathrm{~min}$. Removal rates of COD and chromaticity are slightly lower than the second group of experiments. For the third group of experiments, the Fenton process started $30 \mathrm{~min}$ before the Mn ore tailings were dosed and subject to ozonation for $30 \mathrm{~min}$ at the same time. Removal rate of COD and chromaticity is $61.0 \%$ and $96.7 \%$, respectively.
Due to the complexity of the degradable organic matter in the coking wastewater, the individual oxidation process cannot remove all the organic matters. Researches had found that $\mathrm{O}_{3}$ combined with the Fenton reagent $\mathrm{O}_{3} / \mathrm{Fen}$ ton) showed a high oxidation rate due to synergistic effects while it can produce a large number of $\cdot \mathrm{OH}$ in the $\mathrm{O}_{3} /$ Fenton process (Asaithambi et al. 2017; Li et al. 2015). Compared the second combination (ii) with the third combination (iii), Fenton reagent, $\mathrm{O}_{3}$ and $\mathrm{Mn}$ tailings were all introduced to the combined system with different reaction sequences. Mn oxides are potential oxidizing agents of natural and xenobiotic organic compounds which make them important participants in oxidation-reduction reactions. In addition, the structure of Mn ore tailing surface is uneven and can absorb organics effectively (Liu et al. 2015); the adsorption process follows the pseudo-second-order model (Zheng and Tang 1999). The Mn(III) released by Mn ore tailings will convert into $\mathrm{Mn}$ (II) after reacting with phenols under acid condition, but the Mn(II) shown inconspicuous catalysis as it is difficult to determine whether phenols reactant molecules participate in the release of Mn(II) (Stone 1987). For the third group of experiments, Fenton was applied first to degrade organic matter and convert macromolecules into small molecules, then $\mathrm{Mn}$ ore tailing was dosed to the system. On the one hand, the released $\mathrm{Mn}(\mathrm{II})$ can react with hydrogen peroxide that is not fully reacted in Fenton and produce $\mathrm{OH}$; on the
Fig. 3 Effluent COD (chemical oxygen demand) under different ozone and Mn ore tailings dosages (note the changes of COD)
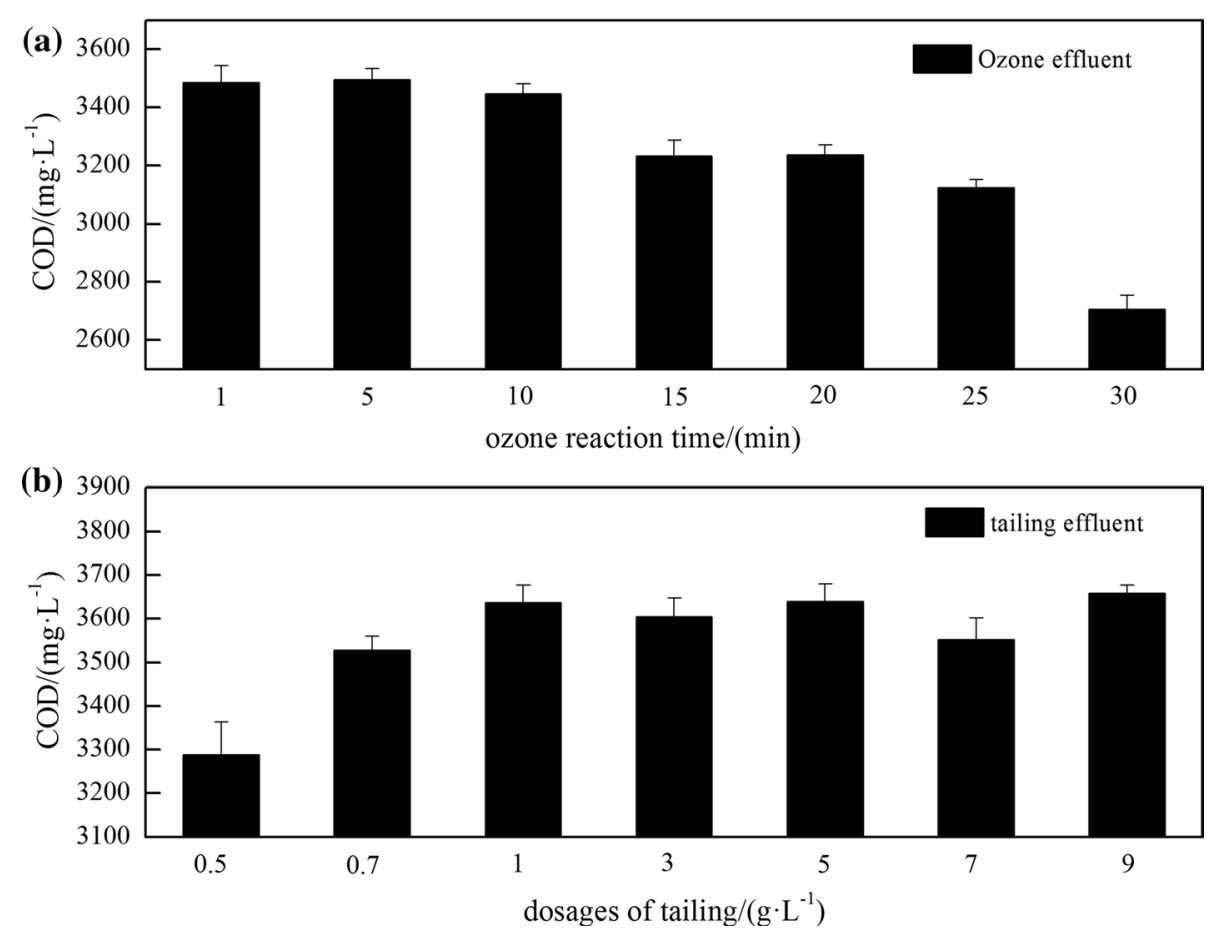
other hand, the remained $\mathrm{Mn}$ (III) can be used as catalyst to convert hydrogen peroxide into superoxide radical $\left(\mathrm{O}_{2} \cdot{ }^{-}\right)$. Some studies also reported that iron and Mn oxides can take full advantage of $\mathrm{H}_{2} \mathrm{O}_{2}$ to degrade organics in the redox process (Chen et al. 2017).

\section{Role of ozone and Mn ore tailing in the combined oxidation processes}

The profiles of COD removal efficiency with different ozonation reaction times and dosages of $\mathrm{Mn}$ tailings at $\mathrm{pH} 4.0$ are shown in Fig. 3. The initial $\mathrm{O}_{3}$ concentration of the reaction is $25 \mathrm{mg} \mathrm{L}^{-1}$. COD removal efficiency of the combined

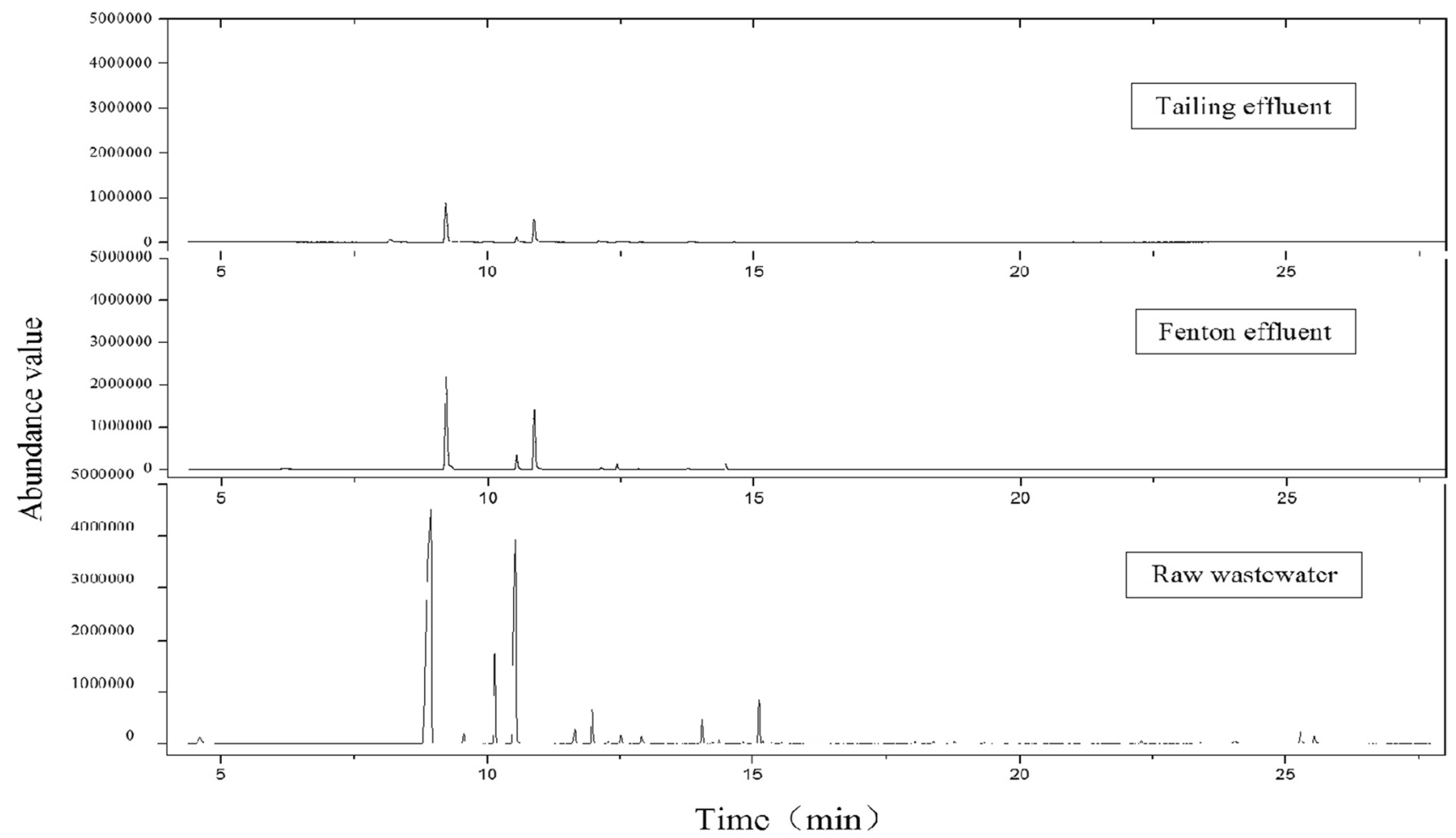

\begin{tabular}{ccccccc}
\hline Main pollutants & $\begin{array}{c}\text { Peak } \\
\text { time } \\
\text { (min) }\end{array}$ & $\begin{array}{c}\text { peak area } \\
\text { (raw } \\
\text { wastewater) }\end{array}$ & $\begin{array}{c}\text { Peak area } \\
\text { (Fenton } \\
\text { effluent) }\end{array}$ & $\begin{array}{c}\text { Removal } \\
\text { rate } \\
(\%)\end{array}$ & $\begin{array}{c}\text { Peak area } \\
\text { (ozone } \\
\text { effluent) }\end{array}$ & $\begin{array}{c}\text { Removal } \\
\text { rate } \\
(\%)\end{array}$ \\
\hline $\begin{array}{c}\text { phenol } \\
\text { aniline }\end{array}$ & 8.931 & 272849586 & 74926948 & 72.5 & 31979357 & 88.3 \\
dimethylphenol & 10.145 & 4691767 & 3045343 & 35.1 & 1362246 & 71.0 \\
2- methyl- & 10.535 & 136252575 & 33396112 & 75.5 & 13458046 & 90.1 \\
pyridine & & & 7180099 & 79.5 & 3099294 & 91.2 \\
quinoline & 14.027 & 8514297 & 1452245 & 82.9 & 843256 & 90.1 \\
indole & 15.112 & 14645444 & 2858492 & 80.5 & 1083759 & 92.6 \\
\hline
\end{tabular}

Fig. 4 GC-MS (gas chromatography-mass spectrometer) results of raw wastewater, Fenton effluent and tailing effluent (note the contaminant components at the peak location) 
process increased with the reaction time in a three-stage pattern (Fig. 3a). Barely any COD removal was observed in this study when the reaction time was less than $10 \mathrm{~min}$. Once the reaction time exceeded $15 \mathrm{~min}$, the COD removal efficiency increased to $10 \%$, while the COD removal efficiency increased to $28 \%$ after $30 \mathrm{~min}$ of reaction. The reaction rate of the ozonation process is mainly limited by the transfer step in the early stage of the reaction (Li et al. 2016a); with the increase in reaction time, a certain amount of $\mathrm{O}_{3}$ was dosed and more $\cdot \mathrm{OH}$ appeared; thus, a corresponding number of target organic compounds were degraded.

As shown in Fig. 3b, the dosages of Mn tailings also had a significant influence on the oxidation process. When the dosage of Mn tailings was between 0.5 and $1.0 \mathrm{~g} \mathrm{~L}^{-1}$, the effluent COD increased with the dosages amount and it reached a relatively stable level when the dosage of tailings was $1.0 \mathrm{~g} \mathrm{~L}^{-1}$. The result is comparable to the literature statement that the loaded Mn contents can increase the catalytic strength of the oxidation process, but it posed negative influence on the catalytic activity when the $\mathrm{Mn}$ contents exceeded to some extend (Huang et al. 2017). The Mn ore tailings used in this study not only contain $\mathrm{Fe} / \mathrm{Mn}$ oxides but also large amount of $\mathrm{SiO}_{2}$; excessive $\mathrm{SiO}_{2}$ covering the surface of $\mathrm{Fe} / \mathrm{Mn}$ oxides can lead to incomplete reaction.

\section{Treatment characteristics and mechanisms of the combined oxidation process}

Composition of the raw wastewater, Fenton effluent and Fenton $+\mathrm{O}_{3} / \mathrm{Mn}$ ore tailings effluent under the optimal operational conditions are demonstrated in Fig. 4. According to the GC-MS database, the organic pollutants in coking wastewater include phenol, aniline, dimethylphenol, 2-methylpyridine, quinoline and indole. Phenol and aniline were chosen as the typical organic pollutions due to their harmful toxicity and long-remaining property (Liu et al. 2016b). Comparing the raw wastewater with Fenton effluent and Fenton $\mathrm{O}_{3} / \mathrm{Mn}$ ore tailings effluent, the organic pollutants can be removed greatly, especially by the combined oxidation process with a suitable reaction time. Most macromolecular organic matters were disappeared after treatment by the Fenton process with a reaction time of $15 \mathrm{~min}$; the pollution peak is no longer obvious after treated by the combined oxidation process with proper reaction times. The removal rate of phenol and aniline in the Fenton method is $72.5 \%$ and $35.1 \%$, respectively, and the removal rate of dimethylphenol, 2-methylpyridine, quinoline and indole is about $80.0 \%$.

Coking wastewater contains a large number of macromolecules organic matter in the pre-reaction. The $\cdot \mathrm{OH}$ produced by Fenton reagent can combine with organic matters and destroy organic chemicals, converting the large macromolecules into small molecules, such as $\mathrm{H}_{2} \mathrm{O}$ and $\mathrm{CO}_{2}$ (Ma et al. 2009). The Fenton method used for removing aniline had been reported by (Zhou et al. 2012). The results presented here are consistent with those of Chu et al. (2012), which reported that during the advanced Fenton oxidation using iron powder and $\mathrm{H}_{2} \mathrm{O}_{2}$, organic compounds such as quinoline and bifuran can react with $\cdot \mathrm{OH}$ and be removed completely; thus, no radicals can be detected for the first $25 \mathrm{~min}$ of the Fenton process, but a typical signal of $\cdot \mathrm{OH}$ can be detected at the reaction time of $1 \mathrm{~h}$ (Fig. 5a-d).
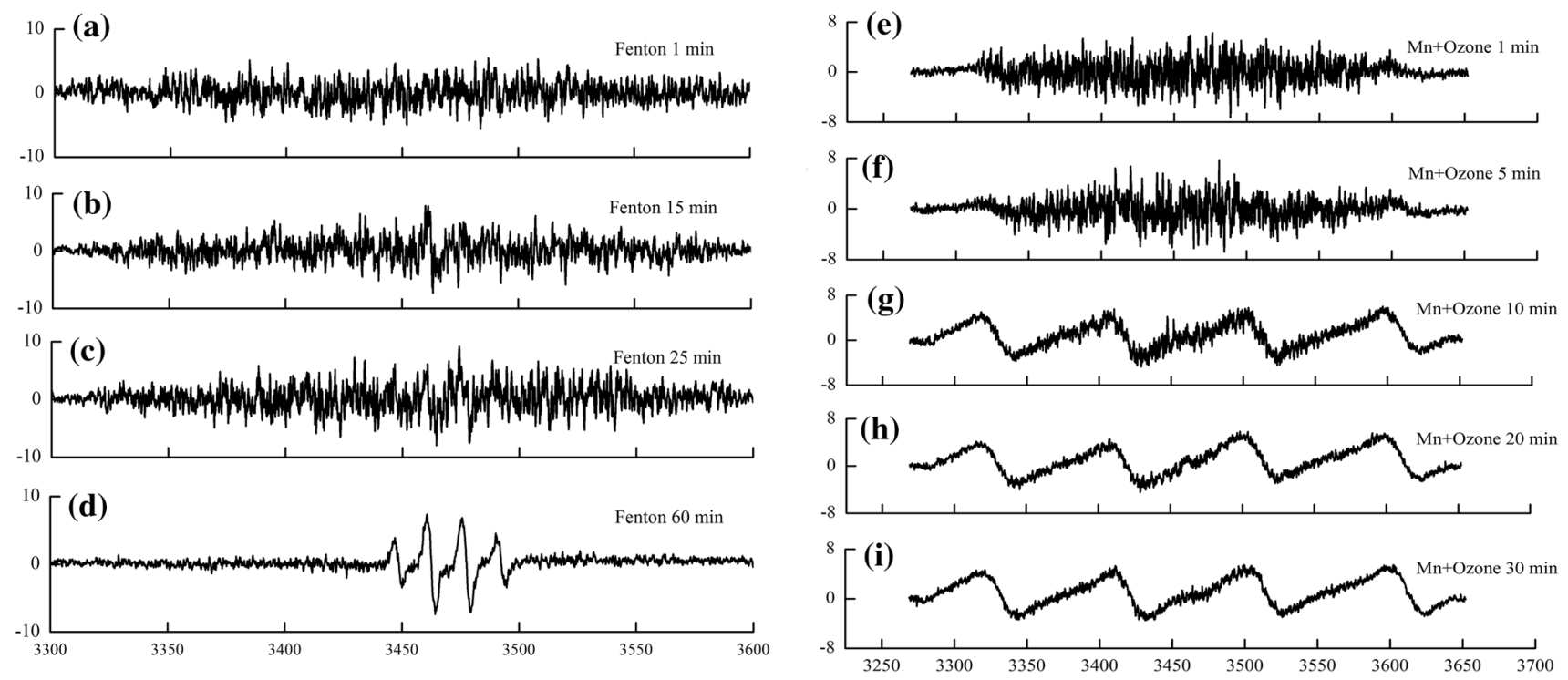

Fig. 5 Generation and change of radicals during the Fenton process (a-d); generation and change of radicals during the Mn ore tailings + ozone process $(\mathbf{e}-\mathbf{i})$ (note the changes of BOD/COD) 
The removal rate of dimethylphenol for aniline after $\mathrm{O}_{3} /$ Mn tailings reaction increased from 35.1 to $71.0 \%$, which was twice as effective as the Fenton process. As shown in Fig. $5 \mathrm{e}-\mathrm{i}$, the $\cdot \mathrm{OH}$ radical peak disappeared immediately in the first $5 \mathrm{~min}$ and later no radicals can be detected due to strong absorption of the Mn ore tailings that absorb $\cdot \mathrm{OH}$ remained in solution to the surface of the manganese ore. With the increase in $\mathrm{O}_{3}$ dosage, more $\cdot \mathrm{OH}$ were generated in the study system since the Mn oxides can accelerate decomposition of $\mathrm{O}_{3}$ to $\cdot \mathrm{OH}$ (Xing et al. 2016). A typical signal of $\mathrm{O}_{2} \cdot{ }^{-}$can be detected, and the signal intensity tends to be increased and more obviously after $10 \mathrm{~min}$ of reaction, because the generated $\cdot \mathrm{OH}$ are transformed into $\mathrm{O}_{2} \cdot{ }^{-}$under the catalysis of $\mathrm{Mn}$ ore tailings ( $\mathrm{Li}$ et al. 2016b). $\mathrm{MnO}_{x}$ can remove organic pollutants more effectively under the condition of heterogeneous catalytic ozonation (Jiang et al. 2016). Due to the large surface of Mn ore tailing, the main catalysis and oxidation reaction were supposed to occur on the surface, following by the direct contact of pollutants with molecular $\mathrm{O}_{3}$ and $\mathrm{O}_{2}{ }^{-}$. The result is consistent with a previously study which indicated that when Mn oxide with carbon materials was used as catalysts for the

Table 1 Effluent COD (chemical oxygen demand) and $\mathrm{BOD}_{5}$ (biochemical oxygen demand) under different pre-treatments (note the comparison of different pre-treatment results)

\begin{tabular}{llll}
\hline & Raw wastewater & Fenton effluent & $\begin{array}{l}\text { Fenton }+\mathrm{O}_{3} / \\
\text { Mn ore tailings } \\
\text { effluent }\end{array}$ \\
\hline $\mathrm{COD}\left(\mathrm{mg} \mathrm{L}^{-1}\right)$ & $5100 \pm 100$ & $3560 \pm 80$ & $2717 \pm 65$ \\
$\mathrm{BOD}_{5}\left(\mathrm{mg} \mathrm{L}^{-1}\right)$ & $372.3 \pm 7.1$ & $879.3 \pm 13.2$ & $1464.5 \pm 17.5$ \\
$\mathrm{BOD}_{5} / \mathrm{COD}$ & 0.073 & 0.247 & 0.539 \\
\hline
\end{tabular}

ozonation of oxalic acid, the reaction mechanisms included both surface reaction and liquid bulk reactions involving $\cdot \mathrm{OH}$ radicals (Orge et al. 2012). Equations (1)-(4) are the main reactions in the combined AOPs (Berlett et al. 1990; Li et al. 2016b; Schönherr et al. 2017).

$\mathrm{Fe}^{2+}+\mathrm{H}_{2} \mathrm{O}_{2}+\mathrm{H}^{+} \rightarrow \mathrm{Fe}^{3+}+\mathrm{H}_{2} \mathrm{O}+\cdot \mathrm{OH}$

$\mathrm{Mn}(\mathrm{II})+\mathrm{O}_{3}+2 \mathrm{H}_{2} \mathrm{O} \rightarrow \mathrm{Mn}(\mathrm{III})+\cdot \mathrm{OH}+\cdot \mathrm{OOH}+\mathrm{O}_{2}$

$\mathrm{Mn}(\mathrm{II})+\mathrm{H}_{2} \mathrm{O}_{2} \rightarrow \mathrm{Mn}(\mathrm{III})+\cdot \mathrm{OH}+\mathrm{OH}^{-}$

$\mathrm{Mn}(\mathrm{III})+\mathrm{H}_{2} \mathrm{O}_{2}+\cdot \mathrm{OH} \rightarrow \mathrm{Mn}(\mathrm{III})+\mathrm{O}_{2}^{--}+\mathrm{H}_{2} \mathrm{O}+\mathrm{H}^{+}$.

After pre-treatment, the biochemical tests of coking wastewater were carried out using $\mathrm{BOD}_{5}$ inoculation method with results shown in Table 1 . The $\mathrm{BOD}_{5} / \mathrm{COD}$ value $(\mathrm{B} / \mathrm{C})$ of raw coking wastewater is only 0.073 , which is difficult to treat biochemically. After the Fenton oxidation, the B/C value is promoted to 0.247 ; but the low $\mathrm{pH}$ value after Fenton treatment is harmful to the subsequent biochemical treatment. Finally, after Mn ore tailings and ozonation treatment, the $\mathrm{B} / \mathrm{C}$ value of the coking wastewater can increase to 0.539 while $\mathrm{O}_{3}$ oxidation was effective in reducing toxicity of two quaternary ammonium compounds and improved their biodegradability. A study also indicated that with single ozonation at $\mathrm{pH} 9.0$ the biodegradability of a landfill leachate can be increased from 0.05 to 0.33 (Amaral-Silva et al. 2016). Biodegradability of the treated effluent, measured as a ratio of $\mathrm{BOD}_{5}$ to $\mathrm{COD}$, improved about 2-3 folds in 30 min due to $\mathrm{O}_{3} / \mathrm{H}_{2} \mathrm{O}_{2}$ oxidation (Khan et al. 2017).
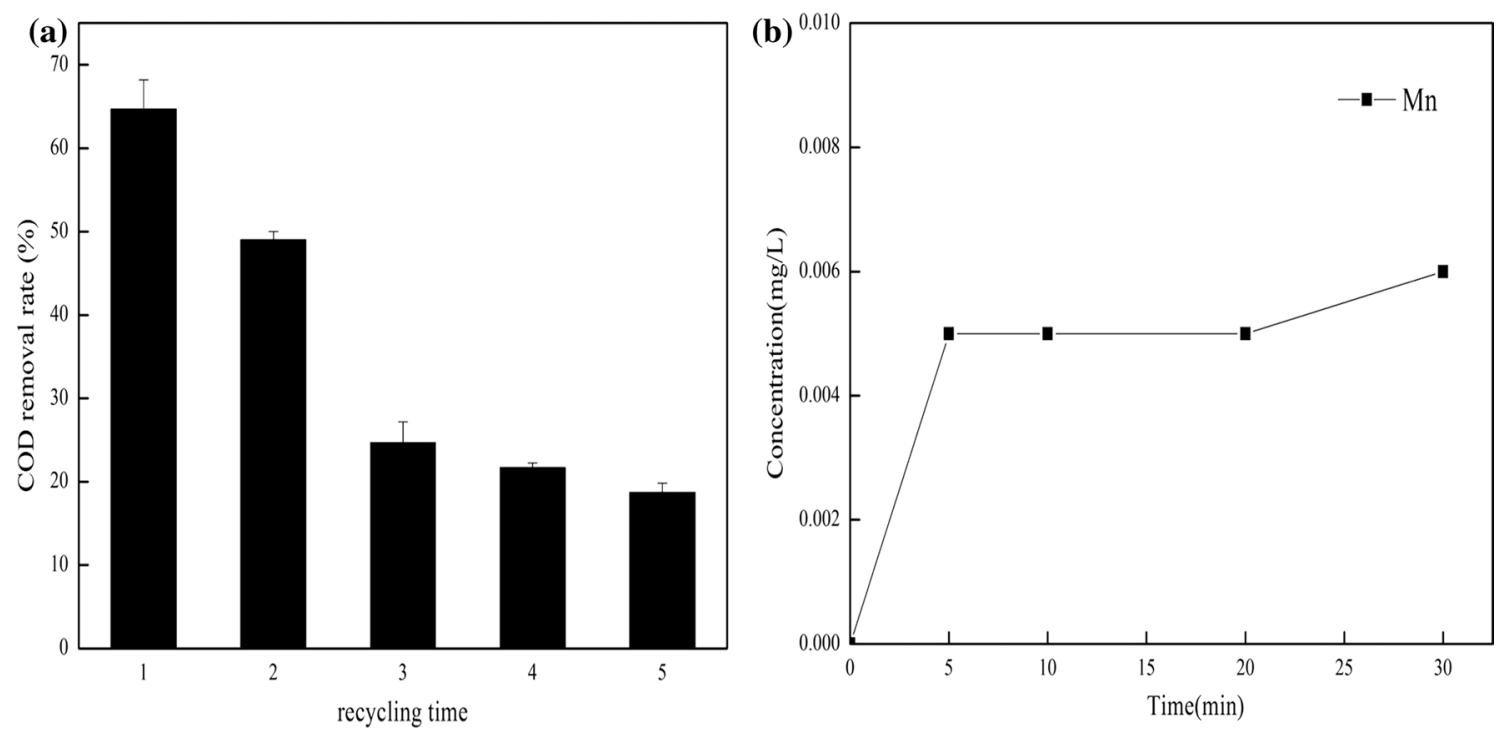

Fig. 6 Recycling (a) and leaching (b) profiles of Mn ore tailings 
The recycling of manganese ore tailings is an important resource utilization. In the process of mine development, there are many environmental problems, endangering human health and destroying the ecological environment. Therefore, it is of far-reaching resource significance for the reuse of manganese ore tailings. The experiments concerning recycling and reusing of Mn ore tailing residue were carried out after the pre-treatment, and the results are shown in Fig. $6 \mathrm{a}$. The removal rate of COD is about $65 \%$ when using Mn ore tailing for the first time, and it decreased with the increase in recycling time. The removal rate is less than $25 \%$ when the recycling time exceeds 3 . In our previous research, the surface of Mn ore tailing turned smoother as the reaction processed, during treatment of low concentration coking wastewater, which resulted in the decrease in catalysis effects (Liu et al. 2015). Mn oxides were applied as heterogeneous catalysts and were recovered by filtration, washed with distilled water and ethyl ether repeatedly previously; it showed that the activity of the catalyst reduced insignificantly after 4 times of reuse (Qi et al. 2011). Concentration of residue metal ions of the Mn ore tailing representing as in the leaching solution is shown in Fig. 6b. From the results, only Mn can be detected, but its concentration does not significantly change with the leaching time. The concentration was $0.005 \mathrm{mg} \mathrm{L}^{-1}$ when the leaching time is $5 \mathrm{~min}$, while it remains almost constant until $20 \mathrm{~min}$; Mn concentration increased only by $0.001 \mathrm{mg} \mathrm{L}^{-1}$ when the leaching time was $30 \mathrm{~min}$. The experimental data indicate that the leaching content of manganese tailings in water is low; considering the operational and recycling cost of full-scale projects, manganese tailings can be processed into filter materials for filling in practical engineering applications. A reactor filled with filter material increases contact of $\mathrm{O}_{3} / \mathrm{Mn}$ and the coking wastewater, improves the oxidation efficiency and can effectively reduce sludge production amount. Also, it is convenient for recycling of waste filter materials after recycling. Because $\mathrm{Mg}^{2+}$ cannot destroy the unity of crystal structure, $\mathrm{MgO}$ has little effect on the characteristics of ceramsite (Zou et al. 2009). It can be combined with other materials to produce high-performance ceramsite, reducing the cost of sludge disposal, which is consistent with sustainable development philosophy.

The combined Mn-AOPs process can not only solve the disposal problem of manganese tailings, but also reduce the chemical dosage cost; compared to traditional technologies, it can save $30-50 \%$ of operating cost and realize economic benefits after calculation, with a total operation cost of 3.77 RMB-Yuan per pre-treated wastewater $\left(\mathrm{m}^{3}\right)$.

\section{Conclusion}

A novel combined process AOP using Mn ore tailings treating coking wastewater was proved to be feasible. Fenton and ozonation were chosen as model oxidation technologies combining with $\mathrm{Mn}$ ore tailings. The optimal combination process is initial Fenton oxidation followed by Mn tailings assisted ozonation (Fenton $+\mathrm{O}_{3} / \mathrm{Mn}$ ore tailings), where its COD and chromaticity removal rates can reach $61.0 \%$ and $96.7 \%$, respectively. Mn ore tailing improves efficiency of AOPs using Mn oxides as a catalyst for the formation of free radicals $\left(\cdot \mathrm{OH}\right.$ and $\left.\mathrm{O}_{2} \cdot{ }^{-}\right)$and oxidation of organic compounds. Oxidation and radicals mainly took place on the surface of Mn ore tailings.

Acknowledgements This work was financially supported by the Shanghai Science International Cooperation Project (STCSM, 18230712300) and the "Shu Guang" Project of Shanghai Municipal Education Commission and Shanghai Education Development Foundation (18SG45).

\section{Compliance with ethical standards}

Conflict of interest The authors have declared no conflict of interest.

\section{References}

Amaral-Silva N, Martins RC, Castro-Silva S, Quinta-Ferreira RM (2016) Ozonation and perozonation on the biodegradability improvement of a landfill leachate. J Environ Chem Eng 4:527533. https://doi.org/10.1016/j.jece.2015.12.002

Asaithambi P, Sajjadi B, Aziz ARA (2017) Integrated ozone-photoFenton process for the removal of pollutant from industrial wastewater. Chin J Chem Eng 25:516-522. https://doi.org/10.1016/j. cjche.2016.10.005

Asghar A, Abdul Aziz AR, Mohd AWDW (2015) Advanced oxidation processes for in situ production of hydrogen peroxide/hydroxyl radical for textile wastewater treatment: a review. J Clean Prod 87:826-838. https://doi.org/10.1016/j.jclepro.2014.09.010

Barriga-Ordonez F, Nava-Alonso F, Uribe-Salas A (2006) Cyanide oxidation by ozone in a steady-state flow bubble column. Miner Eng 19:117-122. https://doi.org/10.1016/j.mineng.2005.09.001

Berlett BS, Chock PB, Yim MB, Stadtman ER (1990) Manganese(II) catalyzes the bicarbonate-dependent oxidation of amino acids by hydrogen peroxide and the amino acid-facilitated dismutation of hydrogen peroxide. Proc Natl Acad Sci USA 87:389393. https://doi.org/10.1073/pnas.87.1.389

Bijan L, Mohseni M (2005) Integrated ozone and biotreatment of pulp mill effluent and changes in biodegradability and molecular weight distribution of organic compounds. Water Res 39:37633772. https://doi.org/10.1016/j.watres.2005.07.018

Chen J, Chen X, Xu W, Xu Z, Chen J, Jia H, Chen J (2017) Hydrolysis driving redox reaction to synthesize $\mathrm{Mn}-\mathrm{Fe}$ binary oxides as highly active catalysts for the removal of toluene. Chem Eng J 330:281-293. https://doi.org/10.1016/j.cej.2017.07.147

Chu LB, Wang JL, Dong J, Liu HY, Sun XL (2012) Treatment of coking wastewater by an advanced Fenton oxidation process using iron powder and hydrogen peroxide. Chemosphere 86:409-414. https://doi.org/10.1016/j.chemosphere.2011.09.007 
Faweya EB, Oniya EO (2012) Radiological safety assessment and physico-chemical characterization of soil mixed with mine tailings used as building materials from oke-kusa mining sites in Ijero, Nigeria. Nat Sci 10:64-71

Feng J, Hu X, Yue PL (2006) Effect of initial solution pH on the degradation of Orange II using clay-based Fe nanocomposites as heterogeneous photo-Fenton catalyst. Water Res 40:641-646. https://doi.org/10.1016/j.watres.2005.12.021

Gilcreas FW (1966) Standard methods for the examination of water and waste water. Am J Public Health Nations Health 56:387388. https://doi.org/10.2105/ajph.56.3.387

Guštin S, Marinšeklogar R (2011) Effect of pH, temperature and air flow rate on the continuous ammonia stripping of the anaerobic digestion effluent. Process Saf Environ Prot 89:61-66. https:// doi.org/10.1016/j.psep.2010.11.001

Huang Y, Sun Y, Xu Z, Luo M, Zhu C, Liang L (2017) Removal of aqueous oxalic acid by heterogeneous catalytic ozonation with $\mathrm{MnO}_{\mathrm{x}} /$ sewage sludge-derived activated carbon as catalysts. Sci Total Environ 575:50-57. https://doi.org/10.1016/j. scitotenv.2016.10.026

Jiang L, Lu L, Xiao S, Chen J (2016) Preparation of a novel manganese oxide-modified diatomite and its aniline removal mechanism from solution. Chem Eng J 284:609-619. https://doi. org/10.1016/j.cej.2015.08.140

Khan AH, Kim J, Sumarah M, Macfie SM, Ray MB (2017) Toxicity reduction and improved biodegradability of benzalkonium chlorides by ozone/hydrogen peroxide advanced oxidation process. Sep Purif Technol 185:72-82. https://doi.org/10.1016/j.seppu r.2017.05.010

Kumar R, Pal P (2012) Response surface-optimized Fenton's pretreatment for chemical precipitation of struvite and recycling of water through downstream nanofiltration. Chem Eng J 210:3344. https://doi.org/10.1016/j.cej.2012.08.036

Kumar R, Pal P (2013) Membrane-integrated hybrid bioremediation of industrial wastewater: a continuous treatment and recycling approach. J Water Reuse Desalin 3:26. https://doi.org/10.2166/ wrd.2013.157

Li XZ, Zhao QL (2001) Efficiency of biological treatment affected by high strength of ammonium-nitrogen in leachate and chemical precipitation of ammonium-nitrogen as pretreatment. Chemosphere 44:37-43. https://doi.org/10.1016/s0045-6535(00)00382 $-9$

Li M, Zeng Z, Li Y, Arowo M, Chen J, Meng H, Shao L (2015) Treatment of amoxicillin by $\mathrm{O}_{3} /$ Fenton process in a rotating packed bed. J Environ Manag 150:404-411. https://doi.org/10.1016/j. jenvman.2014.12.019

Li A et al (2016a) Study on the removal of benzisothiazolinone biocide and its toxicity: the effectiveness of ozonation. Chem Eng $\mathbf{J}$ 300:376-383. https://doi.org/10.1016/j.cej.2016.04.021

Li Y, Sun J, Sun SP (2016b) Mn( $\left.2^{+}\right)$-mediated homogeneous Fentonlike reaction of Fe(III)-NTA complex for efficient degradation of organic contaminants under neutral conditions. J Hazard Mater 313:193-200. https://doi.org/10.1016/j.jhazmat.2016.04.003

Lim BR, Hu HY, Fujie K (2003) Biological degradation and chemical oxidation characteristics of coke-oven wastewater. Water Air Soil Pollut 146:23-33. https://doi.org/10.1023/a:1023923409422

Liu T, Wu K, Zeng L (2012) Removal of phosphorus by a composite metal oxide adsorbent derived from manganese ore tailings.
J Hazard Mater 217-218:29-35. https://doi.org/10.1016/j.jhazm at.2012.01.019

Liu H, Gao S, Zhu M, Chen P, Pan D (2015) Use of manganese/silicon tailing waste for coking wastewater treatment: evaluation of phenol and phenylamine removal efficiencies. Water Air Soil Pollut 226:78. https://doi.org/10.1007/s11270-015-2303-Z

Liu Y, Liu J, Zhang A, Liu Z (2016a) Treatment effects and genotoxicity relevance of the toxic organic pollutants in semi-coking wastewater by combined treatment process. Environ Pollut 220:13-19. https://doi.org/10.1016/j.envpol.2016.04.095

Liu Y, Zhou S, Yang F, Qin H, Kong Y (2016b) Degradation of phenol in industrial wastewater over the $\mathrm{F}-\mathrm{Fe} / \mathrm{TiO}_{2}$ photocatalysts under visible light illumination. Chin J Chem Eng 24:1712-1718. https ://doi.org/10.1016/j.cjche.2016.05.024

Lungen HB (2005) The situation of the Chinese coke making industry. Stahl und Eisen 125(11):S72-S74

Ma H, Zhang X, Ma Q, Wang B (2009) Electrochemical catalytic treatment of phenol wastewater. J Hazard Mater 165:475-480. https:// doi.org/10.1016/j.jhazmat.2008.10.012

Meng X, Ning P, Xu G, Cao H (2017) Removal of coke powder from coking wastewater by extraction technology. Sep Purif Technol 175:506-511. https://doi.org/10.1016/j.seppur.2016.10.015

Orge CA, Orfao JJM, Pereira MFR (2012) Composites of manganese oxide with carbon materials as catalysts for the ozonation of oxalic acid. J Hazard Mater 213:133-139. https://doi.org/10.1016/j. jhazmat.2012.01.066

Peng R, Yu P, Luo Y (2017) Coke plant wastewater posttreatment by Fenton and electro-Fenton processes. Environ Eng Sci 34:89-95. https://doi.org/10.1089/ees.2015.0520

Qi B, Lou LL, Yu K, Bian WY, Liu SX (2011) Selective epoxidation of alkenes with hydrogen peroxide over efficient and recyclable manganese oxides. Catal Commun 15:52-55. https://doi. org/10.1016/j.catcom.2011.08.012

Santo CE, Vilar VJP, Botelho CMS, Bhatnagar A, Kumar E, Rui ARB (2012) Optimization of coagulation-flocculation and flotation parameters for the treatment of a petroleum refinery effluent from a Portuguese plant. Chem Eng J 183:117-123. https://doi. org/10.1016/j.cej.2011.12.041

Schönherr J, Buchheim J, Scholz P, Stelter M (2017) Oxidation of carbon nanotubes with ozone and hydroxyl radicals. Carbon 111:631-640. https://doi.org/10.1016/j.carbon.2016.10.013

Stone AT (1987) Reductive dissolution of manganese(III/Iv) oxides by substituted phenols. Environ Sci Technol 21:979. https://doi. org/10.1021/es50001a011

Su CY, Li WG, Liu XZ, Huang XF, Yu XD (2016) Fe-Mn-sepiolite as an effective heterogeneous Fenton-like catalyst for the decolorization of reactive brilliant blue. Frontiers of Environ Sci Eng 10:37-45. https://doi.org/10.1007/s11783-014-0729-y

Turhan K, Uzman S (2008) Removal of phenol from water using ozone. Desalination 229:257-263. https://doi.org/10.1016/j.desal .2007.09.012

Verma V, Chaudhari PK (2020) Optimization of multiple parameters for treatment of coking wastewater using Fenton oxidation. Arab J Chem 13:5084-5095. https://doi.org/10.1016/j.arabj c. 2020.02.008

Wenzl T, Simon R, Anklam E, Kleiner J (2006) Analytical methods for polycyclic aromatic hydrocarbons (PAHs) in food and the environment needed for new food legislation in the European Union. 
Trends Anal Chem Trends Anal Chem 25:716-725. https://doi. org/10.1016/j.trac.2006.05.010

Xing S, Lu X, Liu J, Zhu L, Ma Z, Wu Y (2016) Catalytic ozonation of sulfosalicylic acid over manganese oxide supported on mesoporous ceria. Chemosphere 144:7-12. https://doi. org/10.1016/j.chemosphere.2015.08.044

Zhang S, Zheng J, Chen Z (2014) Combination of ozonation and biological aerated filter (BAF) for bio-treated coking wastewater. Sep Purif Technol 132:610-615. https://doi.org/10.1016/j.seppu r.2014.06.019

Zhao K, Quan X, Chen S, Yu H, Zhao J (2019) Preparation of fluorinated activated carbon for electro-Fenton treatment of organic pollutants in coking wastewater: the influences of oxygen-containing groups. Sep Purif Technol. https://doi.org/10.1016/j.seppu r.2019.05.058
Zheng H, Tang HX (1999) Adsorption and degradation of phenol on natural manganese ore surfaces. Acta Scientiae Circumstantiae 1999(06):619-624. https://doi.org/10.13671/j.hjkxxb.1999.06.007 (in Chinese)

Zhou L, Hu J, Zhong H, Li X (2012) Study of phenol removal using fluidized-bed Fenton process. Chem Eng Res Des 90:377-382. https://doi.org/10.1016/j.cherd.2011.07.015

Zhu X, Tian J, Liu R, Chen L (2011) Optimization of Fenton and electro-Fenton oxidation of biologically treated coking wastewater using response surface methodology. Sep Purif Technol 81:444450. https://doi.org/10.1016/j.seppur.2011.08.023

Zou JL, Xu GR, Li GB (2009) Ceramsite obtained from water and wastewater sludge and its characteristics affected by $\mathrm{Fe}_{2} \mathrm{O}_{3}$, $\mathrm{CaO}$, and $\mathrm{MgO}$. J Hazard Mater 165:995-1001. https://doi. org/10.1016/j.jhazmat.2008.10.113 


\section{Supplementary Material}

(a)

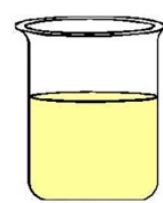

raw coking wastewater

(b)

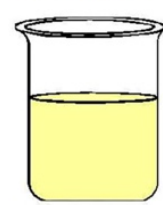

raw coking wastewater

(c)

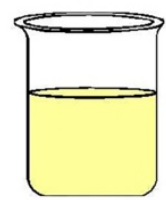

raw coking

wastewater
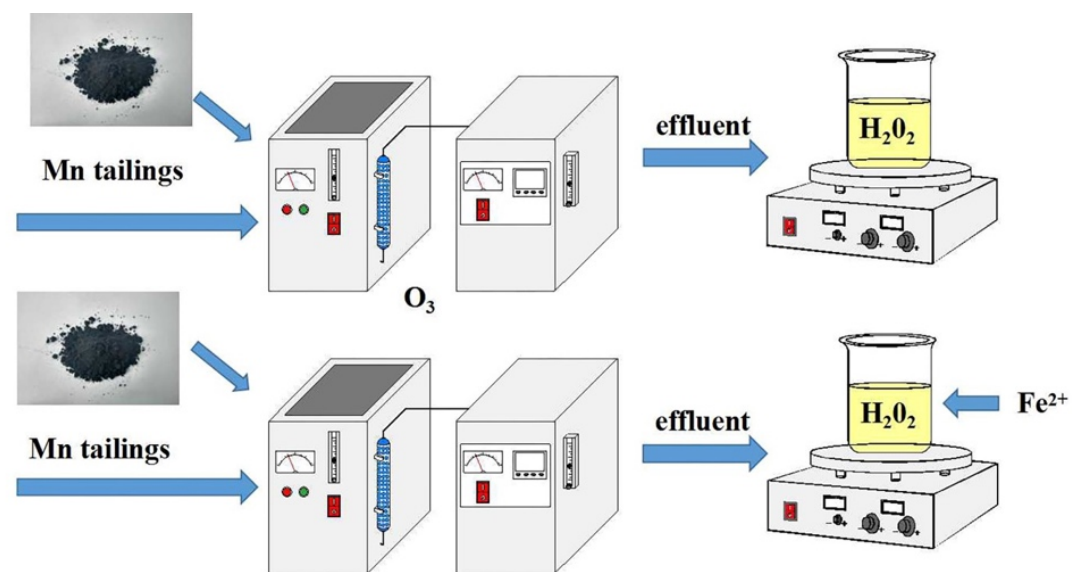

$\mathrm{O}_{3}$

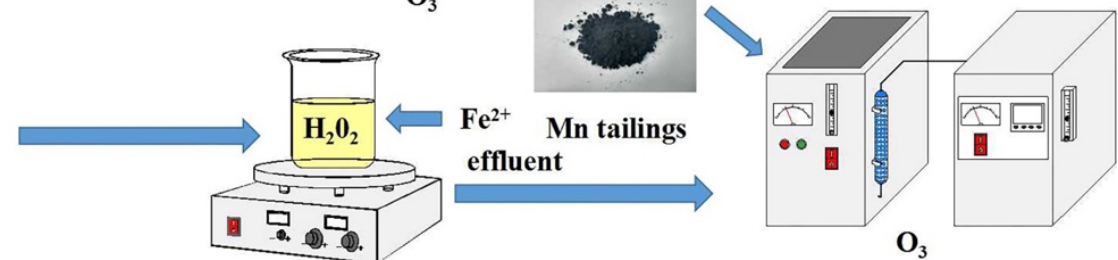

Figure S1. Diagram of the study combination processes (a) O3/Mn ore tailings + H2O2; (b) O3/Mn ore tailings + Fenton and (c) Fenton $+\mathrm{O} 3 / \mathrm{Mn}$ ore tailings

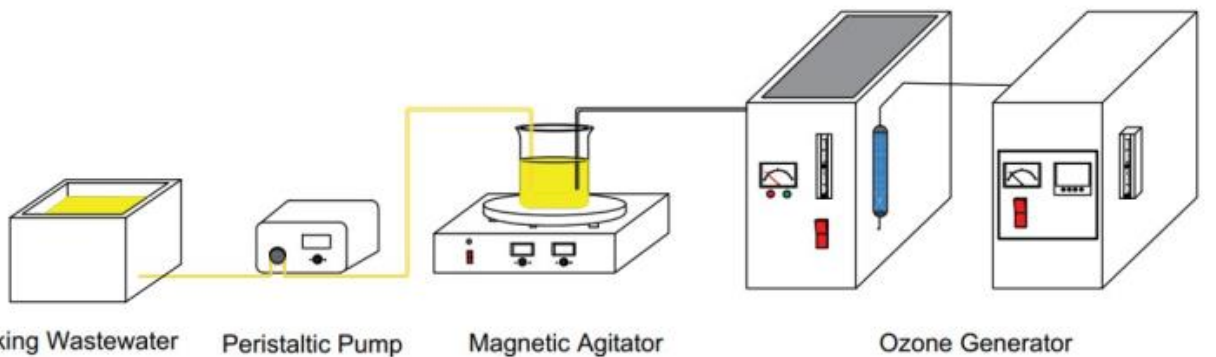

Figure S2. Diagram of the study combination process 